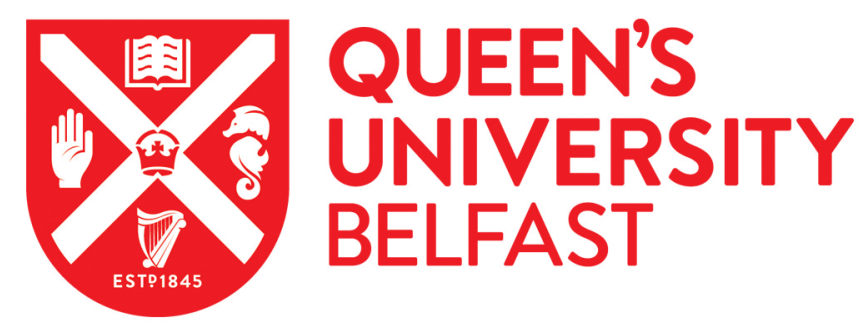

\title{
Multi-walled carbon nanotubes-based magnetic solid-phase extraction for the determination of zearalenone and its derivatives in maize by ultra-high performance liquid chromatography-tandem mass spectrometry
}

Han, Z., Jiang, K., Fan, Z., Diana Di Mavungu, J., Dong, M., Guo, W., Fan, K., Campbell, K., Zhao, Z., \& Wu, Y. (2017). Multi-walled carbon nanotubes-based magnetic solid-phase extraction for the determination of zearalenone and its derivatives in maize by ultra-high performance liquid chromatography-tandem mass spectrometry. Food Control, 79, 177-184. https://doi.org/10.1016/j.foodcont.2017.03.044

Published in:
Food Control

Document Version:

Peer reviewed version

Queen's University Belfast - Research Portal:

Link to publication record in Queen's University Belfast Research Portal

Publisher rights

(C) 2017 Elsevier Ltd. This manuscript is distributed under a Creative Commons Attribution-NonCommercial-NoDerivs License

(https://creativecommons.org/licenses/by-nc-nd/4.0/), which permits distribution and reproduction for non-commercial purposes, provided the author and source are cited.

\section{General rights}

Copyright for the publications made accessible via the Queen's University Belfast Research Portal is retained by the author(s) and / or other copyright owners and it is a condition of accessing these publications that users recognise and abide by the legal requirements associated with these rights.

Take down policy

The Research Portal is Queen's institutional repository that provides access to Queen's research output. Every effort has been made to ensure that content in the Research Portal does not infringe any person's rights, or applicable UK laws. If you discover content in the Research Portal that you believe breaches copyright or violates any law, please contact openaccess@qub.ac.uk. 


\section{Multi-walled carbon nanotubes-based magnetic solid-phase}

2 extraction for the determination of zearalenone and its

3 derivatives in maize by ultra-high performance liquid

4 chromatography-tandem mass spectrometry

6 Zheng Han ${ }^{\text {a,1 }}$, Keqiu Jiang ${ }^{\text {b,1 }}$, Zhichen Fan ${ }^{\text {a, }}$, José Diana Di Mavungu ${ }^{\text {c }}$, Maofeng

7 Dong ${ }^{\text {a }}$, Wenbo Guo ${ }^{\text {a, }}$ Kai Fan ${ }^{\text {a, }}$ Katrina Campbell ${ }^{\mathrm{d}}$, Zhihui Zhao ${ }^{\mathrm{a}, *}$, Yongjiang Wu $8 \mathrm{~b}, *$

$9 \quad{ }^{\text {a }}$ Institute for Agro-food Standards and Testing Technology, Laboratory of Quality \& Safety Risk Assessment for Agro-products (Shanghai), Ministry of Agriculture,

11 Shanghai Academy of Agricultural Sciences, Shanghai 201403, China

b College of Pharmaceutical Sciences, Zhejiang University, 866 Yuhangtang Road, Hangzhou 310058, China

${ }^{\mathrm{c}}$ Laboratory of Food Analysis, Faculty of Pharmaceutical Sciences, Ghent University,

d Institute for Global Food Security, School of Biological Sciences, Queen's

${ }^{1}$ These authors contributed equally to the work.

* Corresponding authors 


\section{Abstract}

A simple and rapid magnetic solid-phase extraction (M-SPE) procedure using multi-walled carbon nanotube-magnetic nanoparticles (MWCNT-MNPs) as sorbents was established for purification of zearalenone (ZEA), $\alpha$-zearalenol ( $\alpha$-ZOL), $\beta$-zearalenol ( $\beta$-ZOL), zearalanone (ZAN), $\alpha$-zearalanol ( $\alpha$-ZAL) and $\beta$-zearalanol $(\beta-Z A L)$ in maize. The main parameters affecting the clean-up efficiency were thoroughly investigated, and high purification efficiencies for all analytes were obtained. The resulting MWCNT-MNP-ultra-high performance liquid chromatography-tandem mass spectrometry (UHPLC-MS/MS) method was validated for maize samples. The matrix effects were greatly minimized using the M-SPE approach, with signal suppression/enhancement values decreased from 69.9-127.6\% to $92.1-103.8 \%$. Consequently, complex matrix-matched calibration curves were not necessary and the calibrations constructed in acetonitrile could be applied for accurate quantification of the targeted mycotoxins in real samples. The average recoveries ranged from 75.8 to $104.1 \%$ and the inter- and intra-day precision values expressed as RSDs, were all lower than $14 \%$. Limits of detection and quantification were in the range of $0.03-0.04$ and $0.07-0.10 \mu \mathrm{g} / \mathrm{kg}$, respectively. The analytical performance of the developed method was also successfully evaluated with maize samples, and this method was proved to be a powerful tool for monitoring ZEA and its derivatives in maize.

Keywords: Magnetic solid-phase extraction; Multi-walled carbon nanotubes; Maize; Zearalenone and its derivatives; Ultra-high performance liquid 
47 


\section{Introduction}

Zearalenone $(\mathrm{ZEA})^{1}$ and its derivatives, including $\alpha$-zearalenol $(\alpha-Z \mathrm{ZL})$, $\beta$-zearalenol ( $\beta$-ZOL), zearalanone (ZAN), $\alpha$-zearalanol ( $\alpha$-ZAL) and $\beta$-zearalanol $(\beta-Z A L)$, are naturally occurring mycotoxins produced by Fusarium species (Desjardins, 2006; El-Kady \& El-Maraghy, 1982; Glenn, 2007). These mycotoxins have been shown to possess estrogenic activity due to its competitive binding to the estrogen receptor, which consequently disrupts the reproductive system and causes abnormal fetal development in animals (Shier, Shier, Xie, \& Mirocha, 2001). Besides the adverse hormonal effects, they have also been implicated in numerous mycotoxicosis of farm animals associated with hepatic and renal lesions in rodents and the reduction of milk production in cows (M Dong, et al., 2010; Maaroufi, Chekir, Creppy, Ellouz, \& Bacha, 1996; Zinedine, Soriano, Molto, \& Manes, 2007). The Joint FAO/WHO Expert Committee on Food Additives (JECFA) has recommended a provisional maximum tolerable daily intake (PMTDI) of $0.5 \mu \mathrm{g} / \mathrm{kg}$ for ZEA. In previous studies (Ibáñez-Vea, González-Peñas, Lizarraga, \& De Cerain, 2012; Iqbal, Asi, Jinap, \& Rashid, 2014; Pleadin, et al., 2012), ZEA and its derivatives have been frequently observed in a variety of cereal crops including maize, wheat, barley and cereal products, representing an important threat to food safety (Oliveira, Rocha,

\footnotetext{
${ }^{1}$ Abbreviations: $\alpha$-ZAL, $\alpha$-zearalanol; $\alpha$-ZOL, $\alpha$-zearalenol; $\beta$-ZAL, $\beta$-zearalanol; $\beta$-ZOL, $\beta$-zearalenol; ELISA, enzyme-linked immunosorbent assay; LOD, limit of detection; LOQ, limit of quantification; LC, liquid chromatography; M-SPE, magnetic solid-phase extraction; ME, matrix effect; MWCNT, multi-walled carbon nanotube; MNP, magnetic nanoparticle; RSD, relative standard deviation; S/N, signal-to-noise ratio; SPE, solid-phase extraction; SSE, signal suppression/enhancement; TEM, transmission electron microscope; TLC, thin-layer chromatography; UHPLC-MS/MS, ultra-high performance liquid chromatography-tandem mass spectrometry; ZAN, zearalanone; ZEA, zearalenone.
} 
Sulyok, Krska, \& Mallmann, 2016; Tralamazza, Bemvenuti, Zorzete, de Souza Garcia, \& Corrêa, 2016). In order to protect consumer safety, legislative limits for ZEA in maize are set by the European Commission, which range from 20 to $400 \mu \mathrm{g} / \mathrm{kg}$ for a variety of products including refined maize oil $(400 \mu \mathrm{g} / \mathrm{kg})$, unprocessed maize (200-350 $\mu \mathrm{g} / \mathrm{kg}$ dependent on milling procedure), maize intended for direct human consumption $(100 \mu \mathrm{g} / \mathrm{kg})$, processed maize based foods for infants and young children $(20 \mu \mathrm{g} / \mathrm{kg})$.

Established analytical methods for ZEA and its derivatives involve thin-layer chromatography (TLC) (Pleadin, et al., 2012), enzyme-linked immunosorbent assay (ELISA) (Pleadin, et al., 2012; Zhan, Huang, Chen, Li, \& Xiong, 2016), biosensors (Välimaa, Kivistö, Leskinen, \& Karp, 2010), liquid chromatography (LC) coupled with mass spectrometry (Han, et al., 2011). TLC has been gradually substituted due to its poor separation efficiency and low sensitivity. ELISA can be provided as a frontline screening method but has limitations in used for legislative quantification because of the cross reactivity. Electrochemical biosensors are based on high affinity interactions between antigen and antibodies, and the lack of specific ligands for ZEA derivatives limits their application (Vidal, et al., 2013). Comparatively, ultra-high performance liquid chromatography-tandem mass spectrometry (UHPLC-MS/MS) coupling the optimal separation efficiency of UHPLC with the high sensitivity and selectivity of MS/MS, seems to be a promising approach for the simultaneous determination of ZEA and its derivatives (Arroyo-Manzanares, Huertas-Pérez, Gámiz-Gracia, \& García-Campaña, 2015). The major disadvantages for this approach 
are matrix effects (MEs) in combination with the limited availability of internal standards for quantification. Complex matrix components may severely affect the ionization process and consequently the accuracy of the method (Stahnke, Kittlaus, Kempe, \& Alder, 2012). Therefore, an appropriate clean-up procedure is required to minimize MEs and establish an accurate and sensitive UHPLC-MS/MS method. Frequently used approaches for clean-up of ZEA and its derivatives are liquid-liquid extraction, solid-phase extraction (SPE), molecularly imprinted polymers, and solid-phase microextraction. SPE-based clean-up procedures offer a number of important advantages, including low organic solvent consumption, high enrichment factor and rapid phase separation (Pyrzynska, Kubiak, \& Wysocka, 2016), and have thus been widely used for purification of different mycotoxin-containing extracts of agricultural products (Giménez, et al., 2013; Lucci, Derrien, Alix, Perollier, \& Bayoudh, 2010; Zollner, Jodlbauer, \& Lindner, 1999). Despite the effectiveness of purification, the conventional SPE encompasses loading, washing and elution steps with slow flow rate, which makes this clean-up procedure time-consuming and labor-intensive. These tedious steps are regarded as bottlenecks for high throughput mycotoxin analysis. In recent years, magnetic solid-phase extraction (M-SPE) has attracted the interest of researchers as a new alternative mode of SPE for sample pretreatment (Geng, Ding, Chen, Li, \& Lin, 2012; Yazdinezhad, Ballesteros-Gómez, Lunar, \& Rubio, 2013; Yilmaz, Alosmanov, \& Soylak, 2015). Compared to conventional SPE, M-SPE is free from tedious process of packing columns and demands smaller volume of sample and solvents for extraction and desorption, 
yielding comparable recoveries of the analytes (Vasconcelos \& Fernandes, 2017), and thus has been used in ZEA and its derivatives purification in several types of food (Gonzalez-Salamo, Socas-Rodriguez, Hernandez-Borges, \& Rodriguez-Delgado, 2017; Moreno, Zougagh, \& Ríos, 2016).

Multi-walled carbon nanotubes (MWCNTs) have become one of the most frequently used constructive nano-materials due to their unique electronic, mechanical, and chemical properties. Previous studies have demonstrated that MWCNTs possess unique features of notable purification and enrichment efficiency as sorbents for heavy metals (Kosa, Al-Zhrani, \& Salam, 2012), pesticide residues (Qin, et al., 2015) and type A trichothecenes (Maofeng Dong, et al., 2015). Magnetic MWCNT composites are hybrids of magnetic nanoparticles (MNPs) and MWCNTs. These composites can be simply synthesized and integrate the unique physical and chemical properties of MWCNTs with the paramagnetic property of MNPs, enabling them to be valuable adsorption materials in the M-SPE procedure. The magnetic MWCNT composites have been applied in combination with chromatographic techniques, for the determination of diverse types of environmental pollutants (pesticide and drug residues, heavy metals and bisphenol A, etc.) (Jiao, et al., 2012; Tarigh \& Shemirani, 2013; Xu, et al., 2013). With regard to ZEA and its derivatives, a MNP-MWCNT-nanoC ${ }_{18} \mathrm{SiO}_{2}$ composite was synthesized and applied for purification of ZEA and its derivatives. Although this material presented several advantages, the procedure for the synthesis of MNP-MWCNT-nanoC ${ }_{18} \mathrm{SiO}_{2}$ composite was very complicated. Moreover, the matrix effects could not be eliminated by this material and 
complex matrix-matched calibration curves are still necessary for accurate quantification (Moreno, Zougagh, \& Ríos, 2016).

In the present study, a simple, rapid and reliable M-SPE procedure using magnetic MWCNTs as sorbents for the simultaneous purification and enrichment of ZEA and its derivatives was developed. The procedure was implemented for maize and the resulting clean extracts were then analyzed by UHPLC-MS/MS. The established method was extensively validated according to the Commission Decision 2002/657/EC, and was then successfully applied to monitor the occurrence of ZEA and its derivatives in real-life maize samples collected in China.

\section{Material and methods}

\subsection{Chemicals and materials}

The MWCNTs ( $8 \mathrm{~nm}$ i.d., $10-30 \mu \mathrm{m}$ length, $500 \mathrm{~m}^{2} / \mathrm{g}$ ) were purchased from XF Nano Materials Tech Co. Ltd. (Nanjing, Jiangsu, China). All organic solvents, acids, alkalis and salts were HPLC or analytical grade. Acetonitrile, methanol and acetone were purchased from Merck (Darmstadt, Germany). Ammonium acetate, formic acid, concentrated ammonium hydroxide, sodium hydroxide $(\mathrm{NaOH})$, ferric chloride hexahydrate $\left(\mathrm{FeCl}_{3} \cdot 6 \mathrm{H}_{2} \mathrm{O}\right)$ and ferrous chloride tetrahydrate $\left(\mathrm{FeCl}_{2} \cdot 4 \mathrm{H}_{2} \mathrm{O}\right)$ were provided by Aladdin Co. (Shanghai, China). Water used throughout the study was purified using a Milli-Q system (Milli-pore, Billerica, MA, USA). The standards of ZEA, $\alpha$-ZOL, $\beta$-ZOL, ZAN, $\alpha$-ZAL and $\beta$-ZAL were obtained from Sigma-Aldrich (St. Louis, MO, USA) and dissolved in acetonitrile to prepare $10 \mu \mathrm{g} / \mathrm{mL}$ of stock 
solutions. The stock solutions were stored at $-20^{\circ} \mathrm{C}$ in the dark.

A total of 20 maize samples (250g each) were randomly collected from different supermarkets in Shanghai, China. All samples were ground into powders, passed through a $2 \mathrm{~mm}$ sieve, maintained in sealed bags in dark at room temperature.

\subsection{Preparation of $M W C N T-M N P s$}

The MWCNT-MNPs were synthesized according to Zhang and Shi (2012) with some modifications: firstly, $300 \mathrm{mg}$ of MWCNTs were added into $250 \mathrm{~mL}$ of water in a $500 \mathrm{~mL}$ three-necked flask, and ultrasonicated for $1 \mathrm{~h}$ to enable the particles to be well dispersed. Then, $\mathrm{FeCl}_{3} \cdot 6 \mathrm{H}_{2} \mathrm{O}(810 \mathrm{mg})$ and $\mathrm{FeCl}_{2} \cdot 4 \mathrm{H}_{2} \mathrm{O}(300 \mathrm{mg})$ were added and the flask was kept in a magnetic stirring thermostatic water bath. Half an hour later, $1 \mathrm{~mol} / \mathrm{L} \mathrm{NaOH}$ solution was slowly added to bring the $\mathrm{pH}$ to approximately 12 , and the reaction was allowed to proceed for another $2 \mathrm{~h}$. During the entire reaction process, the temperature was set at $60{ }^{\circ} \mathrm{C}$ and the flask was kept under nitrogen gas protection. After cooling to room temperature, the black precipitates (MWCNT-MNPs) were magnetically collected, washed with water at least three times, dried at $80{ }^{\circ} \mathrm{C}$ and ground into powder for use. The synthesized materials were characterized using a JEM-1230 transmission electron microscope (TEM; JEOL Ltd., Tokyo, Japan) operated at $80 \mathrm{kV}$, under high vacuum $\left(10^{-5} \mathrm{~Pa}\right)$, at room temperature.

\subsection{Sample pretreatment}

\subsubsection{Optimization of M-SPE procedure for sample pretreatment}

To achieve the optimal performance of the M-SPE procedure with MWCNT-MNPs 
174

as adsorbents, several parameters were investigated including desorption solvent, adsorption solution, adsorption time, MWCNT-MNPs amount by using spiked sample extractions (50 $\mathrm{ng} / \mathrm{mL}$ for each analyte).

\subsubsection{Sample preparation}

Each sample $(2.0 \mathrm{~g})$ was accurately weighed into a $50 \mathrm{~mL}$ centrifuge tube. After maceration with $10 \mathrm{~mL}$ of acetonitrile/water $(84 / 16, \mathrm{v} / \mathrm{v})$ for $5 \mathrm{~min}$, the sample was ultrasonicated for $40 \mathrm{~min}$ and then centrifuged at $4000 \mathrm{~g}$ for $5 \mathrm{~min}$. An aliquot $(5 \mathrm{~mL})$ of supernatant was collected for M-SPE purification. The supernatant was first dried by nitrogen gas at $50^{\circ} \mathrm{C}$, and re-dissolved with $5 \mathrm{~mL}$ of acetonitrile/water $(5 / 95, \mathrm{v} / \mathrm{v})$. Then, $20 \mathrm{mg}$ of MWCNT-MNPs were added. The mixture was vortexed for $3 \mathrm{~min}$ to enable the targeted mycotoxins to interact with and be adsorbed on MWCNT-MNPs. Afterwards, a magnet was placed under the centrifuge tube so that MWCNT-MNPs were magnetically collected and the supernatant was poured off. Then, the mycotoxins were desorbed with $10 \mathrm{~mL}$ of acetone containing $0.5 \%$ formic acid by ultrasonication for $5 \mathrm{~min}$. The MWCNT-MNPs were magnetically gathered again and the desorption solution was collected, dried under a soft stream of nitrogen gas at $50{ }^{\circ} \mathrm{C}$, re-dissolved in $1 \mathrm{~mL}$ of acetonitrile, passed through a $0.22 \mu \mathrm{m}$ nylon filter and ready for analysis by UHPLC-MS/MS. A general scheme for M-SPE is shown in Fig.1.

\subsection{UHPLC-MS/MS analysis}

UHPLC was performed via a Waters Acquity UHPLC system (Waters, Milford, MA, 
USA). Separation was achieved at $40{ }^{\circ} \mathrm{C}$ on a Poroshell EC-C18 column $(100 \mathrm{~mm} \times$ $3.0 \mathrm{~mm}, 2.7 \mu \mathrm{m})$ (Agilent, USA). The mobile phase consisted of (A) methanol and (B) water containing $5 \mathrm{~mol} / \mathrm{L}$ ammonium acetate, and a linear gradient elution program was applied as follows: initial 50\% A, $4 \min 70 \%$ A, $6 \min 75 \%$ A, $7 \min 75 \%$ A, 7.2 min $50 \% \mathrm{~A}$ and hold on for another $1.8 \mathrm{~min}$ for equilibration, giving a total run time of $9 \mathrm{~min}$. The mobile phase flow rate was $0.35 \mathrm{~mL} \mathrm{~min}^{-1}$ and the injection volume was $3 \mu \mathrm{L}$.

The separated compounds were analyzed by a Waters XEVO TQ-S mass spectrometer (Waters, Milford, MA, USA) with an electrospray ionization source operated in negative mode (ESI-). The MS/MS conditions were set as follows: source temperature, $150{ }^{\circ} \mathrm{C}$; desolvation temperature, $500{ }^{\circ} \mathrm{C}$; cone gas flow, $30 \mathrm{~L} / \mathrm{h}$; desolvation gas flow, $1000 \mathrm{~L} / \mathrm{h}$. A multiple reaction monitoring (MRM) acquisition method was developed for the targeted analytes, and the conditions were optimized for each mycotoxin by direct infusion (Table S1, Supplementary Data). Data processing was performed by MassLynx v4.1 and Targetlynx (Waters).

\subsection{Evaluation of the MEs}

The stock solutions were diluted with acetonitrile and blank matrix, respectively, to yield a sequence of concentrations $(0.1,0.2,0.5,1,2,5,10,20,50,100,200$ and 500 $\mathrm{ng} \mathrm{mL}^{-1}$ ) for each analyte. Signal suppression/enhancement (SSE), calculated by comparing the slope of the calibration plot of the standards spiked in the matrix to that of the standards in acetonitrile, was used to evaluate the MEs. 


\subsection{Method validation}

Mixed standard solutions of six analytes at 12 different concentrations $(0.1,0.2,0.5$, $1,2,5,10,20,50,100,200$ and $500 \mathrm{ng} / \mathrm{mL}$ ) were prepared in acetonitrile. Calibration curves were constructed by plotting the responses versus analyte concentrations. The sensitivity was evaluated by determining limit of detection (LOD) and limit of quantification (LOQ), designed as the concentrations of the analytes that resulted in a signal-to-noise ratio $(\mathrm{S} / \mathrm{N})$ of 3 and 10 in matrix, respectively. The recovery, intra- and inter-day precision tests were all performed on non-contaminated samples. Fifteen portions $(2 \mathrm{~g})$ of the blank sample were spiked with low, intermediate and high concentration levels $(5 \mu \mathrm{g} / \mathrm{kg}, 50 \mu \mathrm{g} / \mathrm{kg}$ and $200 \mu \mathrm{g} / \mathrm{kg})$ of each standard, while three additional portions were used as control. All samples were pretreated as described in Section 2.3. The recovery was calculated by comparing the determined concentrations of the analyte with the theoretical values. The relative standard deviations (RSDs) at three concentration levels on the same day were used for evaluation of the intra-day precision, whereas the inter-day precision was assessed using values from five consecutive days.

\section{Results and discussion}

\subsection{Optimization of UHPLC-MS/MS conditions}

Three candidate columns with different lengths and particle sizes i.e. (1) Agilent Poroshell EC-C18 column (100 mm × $3.0 \mathrm{~mm}, 2.7 \mu \mathrm{m}$; Agilent, USA), (2) BEH C18 column $(100 \mathrm{~mm} \times 2.1 \mathrm{~mm}, 1.7 \mu \mathrm{m}$; Waters, USA) and (3) HSS T3 column $(100 \mathrm{~mm}$ 

because the highest responses and best separation efficiency could be obtained for all mycotoxins (Fig. S1A, Supplementary material), and was further applied to analyze ZEA and its derivatives in spiked maize matrices $(0.1-500 \mathrm{ng} / \mathrm{mL})$. The results clearly showed that all targeted analytes could be completely separated from each other without any interference in maize matrices, and thus, Agilent Poroshell EC-C18 column $(100 \mathrm{~mm} \times 3.0 \mathrm{~mm}, 2.7 \mu \mathrm{m}$; Agilent, USA) was selected in the current research

245 Different mobile phases were also tested: (1) methanol-water, (2) methanol-water containing $0.1 \%$ formic acid, (3) methanol-water containing $5 \mathrm{mmol} / \mathrm{L}$ ammonium acetate, (4) methanol-water containing $0.1 \%$ formic acid and $5 \mathrm{mmol} / \mathrm{L}$ ammonium retention times of approximately $4.45 \mathrm{~min}$ for $\beta$-ZAL, $4.80 \mathrm{~min}$ for $\beta-Z \mathrm{ZL}, 5.35 \mathrm{~min}$

251 for $\alpha$-ZAL, $5.60 \mathrm{~min}$ for $\alpha-Z O L, 5.76 \mathrm{~min}$ for ZAN and $5.98 \mathrm{~min}$ for ZEA, respectively. Among the five mobile phases investigated, the responses were the highest for all analytes when mobile phase (3) was applied (Supplementary material, Fig. S1B). Therefore, methanol-water containing $5 \mathrm{mmol} / \mathrm{L}$ ammonium acetate was

255 finally chosen as the mobile phase.

\subsection{Characterization of MWCNT-MNPs}

TEM analysis was applied to collect information about the morphology and structural changes of the obtained composites as a measure of the reaction product as 
a valuable and effective adsorption material for the M-SPE procedure. The TEM image of the synthesized MWCNT-MNPs is provided in Fig.1A. As shown in the microgram (100 nm scale), the black dots of nanoparticles $\left(\mathrm{Fe}_{3} \mathrm{O}_{4}\right)$, synthesized using $\mathrm{FeCl}_{2} \cdot 4 \mathrm{H}_{2} \mathrm{O}$ and $\mathrm{FeCl}_{3} \cdot 6 \mathrm{H}_{2} \mathrm{O}$, were attached uniformly onto the surface of the MWCNTs, indicating that the MWCNT-MNPs have been successfully synthesized and can be applied for the purification of target analytes in samples.

\subsection{Optimization of the M-SPE procedure}

To achieve optimal performance of M-SPE procedure with MWCNT-MNPs as adsorbents, several parameters were investigated including adsorption solution, adsorption time, MWCNT-MNPs amount and desorption solvent by using spiked sample extractions (50 $\mathrm{ng} / \mathrm{mL}$ for each analyte).

\subsubsection{Desorption solvent}

First, three frequently used organic solvents, i.e., acetone, acetonitrile and methanol, were investigated as the desorption solvent (other conditions were the same as described in section 2.3.2). Unsatisfactory recoveries ranging from 43.0 to $83.4 \%$ were obtained (Fig. 2). Then, formic acid (0.5\%) and ammonium hydroxide $(0.5 \%)$ were added into the desorption solvents (5/995, formic acid or ammonium hydroxide/desorption solvent, v/v) to improve the recoveries. Compared to the original solvents, the desorption power of the solutions containing formic acid $(0.5 \%)$ tremendously improved, resulting in higher recoveries for the targeted mycotoxins, whereas ammonia (0.5\%) did not positively affect the desorption efficiency (Fig 2). This indicated that the adsorption performance of MWCNT-MNPs was strongly 
influenced by the $\mathrm{pH}$. The highest recoveries, in the range of $77.0-105.3 \%$, were achieved when acetone containing $0.5 \%$ formic acid was used.

Further, the influence of the volumes of the desorption solvent in the range of 3 to 15 $\mathrm{mL}$ was assessed. The recoveries of all analytes rose when the volume increased from 3 up to $10 \mathrm{~mL}$, but remained almost constant with further increase of the volume (10 to $15 \mathrm{~mL}$ ) (Fig. 3A). Consequently, in the final method, $10 \mathrm{~mL}$ of the acetone containing $0.5 \%$ formic acid was used.

\subsubsection{Adsorption solutions}

To ensure the adsorption of all the target analytes on the MWCNT-MNPs, the effect of the acetonitrile content in extract $(0,2 \%, 5 \%, 10 \%$ and $20 \%)$ on the adsorption process was investigated. The results (Fig.3B) indicated that the adsorption efficiency of MWCNT-MNPs significantly increased with the decreasing percentages of acetonitrile in the adsorption solutions. When extracts containing $20 \%$ of acetonitrile were used, low recoveries (63.5 to $75.8 \%$ ) were observed. Decreasing the percentage of acetonitrile from $20 \%$ to $10 \%$, acceptable recoveries $(73.0-93.2 \%)$ were obtained for most of the analytes except $\alpha$-ZOL (68.9\%). Satisfactory recoveries (76.5-103.5\%) were obtained for all analytes when the acetonitrile content was 5\% or lower. Consequently, it was decided to limit the acetonitrile content in adsorption solution to $5 \%$ in further experiments.

\subsubsection{Adsorption time}

The adsorption time in the range of 1-6 min was investigated. As shown in Fig. 3C, the recoveries dramatically increased for all analytes going from 1 to 3 min adsorption 
time, they then remained constant between 3 to $6 \mathrm{~min}$. To ensure efficient adsorption of all mycotoxins on the MWCNT-MNPs while keeping the operation time short, the adsorption time was set to $3 \mathrm{~min}$.

\subsubsection{MWCNT-MNPs amount}

Different amounts of MWCNT-MNPs (10, 20, 30 and $40 \mathrm{mg}$ ) were compared (Fig. 3D). Satisfactory recoveries in the range of $77.9-105.3 \%$ were obtained for ZEA, $\beta$-ZOL, ZAN, $\alpha$-ZAL and $\beta$-ZAL in the whole range of MWCNT-MNP amount investigated. On the other hand, $\alpha$-ZOL was tightly adsorbed on the sorbent and could not be efficiently desorbed when $30 \mathrm{mg}$ or $40 \mathrm{mg}$ of MWCNT-MNPs were used, resulting in unsatisfactory recoveries, i.e.68.6\% and 62.9\%, respectively. When $10 \mathrm{mg}$ of MWCNT-MNPs were used, the repeatability of the clean-up process was not good, with the RSDs higher than $20 \%$. Therefore, the amount of sorbents was set to $20 \mathrm{mg}$.

\subsection{Evaluation of the clean-up method}

To characterize the established clean-up method, the visually observable features and the extent of MEs for each of the six mycotoxins for the sample extracts before and after M-SPE purification were assessed. As shown in Fig.4A, maize extract purified by M-SPE procedure was colorless and transparent, indicating that the established clean-up method could efficiently remove the pigments and impurities from the matrices so as to minimize the interferences in MS/MS analysis. The MEs data (Fig. 4B) were in good agreement with the visual appearance of the extracts. Satisfactory MEs data, ranging from 92.1 to $103.8 \%$ SSE, were observed for the purified extracts, while a conspicuous influence of the matrix components was 
observed (69.9-127.6\% SSE) for the crude extracts. Compared to the method reported by Moreno et al. (2016), the method described here presented some advantages. Since MEs were successfully eliminated using the proposed clean-up procedure, complex matrix-matched calibration curves were not necessary and calibrations constructed in acetonitrile could be used for accurate quantification of the targeted mycotoxins, which significantly reduced the labor and the amount of materials needed, and obviously resulted in high efficiency. This ultimately makes it possible to perform the analysis with ease, high sensitivity and reduced cost.

\subsection{Method validation}

Calibration curves of the six analytes in neat solvent are shown in Table 1. Good linear relationships with coefficients of determination $\left(\mathrm{R}^{2}\right) \geq 0.993$ were obtained over the range of $0.1-500 \mathrm{ng} / \mathrm{mL}$ for all targeted mycotoxins in acetonitrile. The LOD and LOQ values were in range of $0.03-0.04 \mu \mathrm{g} / \mathrm{kg}$ and $0.07-0.10 \mu \mathrm{g} / \mathrm{kg}$, respectively. Satisfactory recoveries with mean values in the range of $75.8-104.1 \%$ were obtained (Table 2). The RSDs were in the range of $3.4-11.2 \%$ and $3.2-13.2 \%$ for the intra-day precision and for the inter-day precision, respectively. The validation data described above clearly indicated that the analytical method was accurate and repeatable, and could be applied for simultaneous analysis of ZEA and its derivatives in maize.

\subsection{Application to maize samples}

To further evaluate the applicability of the established method, a total of 50 maize samples were analyzed. As shown in Table S2 (Supplementary data), in 47 samples 
ZEA and its derivatives were detected at concentration levels in the range of $0.10-3613.03 \mu \mathrm{g} / \mathrm{kg}$. ZEA was the most prevalent mycotoxin with concentrations ranging from 0.18 to $3613.03 \mu \mathrm{g} / \mathrm{kg}$. It is worth noting that ZEA contents in 4 samples exceeded the maximum regulatory limits set by the EU for maize intended for direct human consumption and if they were considered for consumption by young children then 9 samples exceeded the limit (Oliveira, et al., 2016), indicating a concern for food safety. $\alpha$-ZOL and $\beta$-ZOL were also frequently detected (incidences of $38 \%$ and $44 \%$ ) with the concentration levels ranging from 0.10 to $13.52 \mu \mathrm{g} / \mathrm{kg}$ and from 0.11 to $16.13 \mu \mathrm{g} / \mathrm{kg}$, respectively. A total of 10 samples contained ZAN with the concentrations in the range of $0.13-37.60 \mu \mathrm{g} / \mathrm{kg}$. $\alpha$-ZAL and $\beta-\mathrm{ZAL}$ were detected, in trace amounts $(0.71$ and $0.45 \mu \mathrm{g} / \mathrm{kg}$, respectively), in only one sample. MRM chromatograms of the six analytes in acetonitrile and in a contaminated maize sample (No.16) are shown in Fig. S2 (Supplementary data). To demonstrate the trueness of data generated with the new developed method, a comparison between the new developed method and the reference method in China (GB/T 23504-2009) was performed by determination of two positive samples (No. 6 and No. 15). The determination results obtained by the standard method and the current method were basically consistent (Table S3, supplementary data). Data from the present study confirmed previous reports (Oliveira, et al., 2016; Pleadin, et al., 2012) on the frequent contamination of maize with ZEA and its derivatives resulting in high potential health risks to humans and animals. These results demonstrated that analytical tools such as the method proposed in the present study for rapid and reliable 
determination of ZEA and its derivatives in maize are essential, and could be used in

369 the future in support of the continuous monitoring efforts.

\section{Conclusion}

MWCNT-MNPs were successfully prepared and used as M-SPE sorbents for simultaneous purification of ZEA and its derivatives in maize. The established M-SPE approach was demonstrated to be rapid, effective and efficient, and is therefore a suitable alternative to the traditional SPE that is often tedious and time-consuming due to the packing step and slow solvent follow rates. Coupled with UHPLC-MS/MS detection, satisfactory sensitivities, linearities, recoveries and precisions were obtained. When the validated method was applied to determine the natural occurrence of mycotoxins in maize samples, up to $95 \%$ of the samples were found to be contaminated with ZEA and its derivatives. The high incidence of this type of mycotoxins in maize highlighted the importance of the current work, which provided food safety authorities and researchers with a valuable tool for monitoring ZEA and its derivatives in maize.

\section{Acknowledgements}

This work was supported by the National Natural Science Foundation of China [Grant No. 31671950], Shanghai Agriculture Commission Project [Grant No. 3-2, 2014), Shanghai Science and Technology Innovation Action Plan Project [Grant No. $15142201500]$. 


\section{References}

Arroyo-Manzanares, N., Huertas-Pérez, J. F., Gámiz-Gracia, L., \& García-Campaña, A. M. (2015). Simple and efficient methodology to determine mycotoxins in cereal syrups. Food Chemistry, 177, 274-279.

Commission Regulation (EC) No 1126/2007 of 28 September 2007 amending regulation (EC) No 1881/2006 setting maximum levels for certain contaminants in foodstuffs as regards Fusarium toxins in maize and maize products. Official Journal of the European Union L, 255.

Desjardins, A. E. (2006). Fusarium mycotoxins: chemistry, genetics, and biology: American Phytopathological Society (APS Press).

Dong, M., He, X., Tulayakul, P., Li, J.-Y., Dong, K.-S., Manabe, N., Nakayama, H., \& Kumagai, S. (2010). The toxic effects and fate of intravenously administered zearalenone in goats. Toxicon, 55(2), 523-530.

Dong, M., Si, W., Jiang, K., Nie, D., Wu, Y., Zhao, Z., De Saeger, S., \& Han, Z. (2015). Multi-walled carbon nanotubes as solid-phase extraction sorbents for simultaneous determination of type A trichothecenes in maize, wheat and rice by ultra-high performance liquid chromatography-tandem mass spectrometry. Journal of Chromatography A, 1423, 177-182.

El-Kady, I., \& El-Maraghy, S. (1982). Screening of zearalenone-producing Fusarium species in Egypt and chemically defined medium for production of the toxin. Mycopathologia, 78(1), 25-29. 
GB/T 23504-2009. Determination of zearalenone in food — High performance Iiquid chromatographic method with immunoaffinity column clean-up. National Standards of the People's of China.

Geng, Y., Ding, M., Chen, H., Li, H.-F., \& Lin, J.-M. (2012). Preparation of hydrophilic carbon-functionalized magnetic microspheres coated with chitosan and application in solid-phase extraction of bisphenol $\mathrm{A}$ in aqueous samples. Talanta, 89, 189-194.

Giménez, I., Herrera, M., Escobar, J., Ferruz, E., Lorán, S., Herrera, A., \& Ariño, A. (2013). Distribution of deoxynivalenol and zearalenone in milled germ during wheat milling and analysis of toxin levels in wheat germ and wheat germ oil. Food Control, 34(2), 268-273.

Glenn, A. (2007). Mycotoxigenic Fusarium species in animal feed. Animal Feed Science and Technology, 137(3), 213-240.

Gonzalez-Salamo, J., Socas-Rodriguez, B., Hernandez-Borges, J., \& Rodriguez-Delgado, M. A. (2017). Core-shell poly(dopamine) magnetic nanoparticles for the extraction of estrogenic mycotoxins from milk and yogurt prior to LC-MS analysis. Food Chem, 215, 362-368.

Han, Z., Ren, Y., Zhou, H., Luan, L., Cai, Z., \& Wu, Y. (2011). A rapid method for simultaneous determination of zearalenone, $\alpha$-zearalenol, $\beta$-zearalenol, zearalanone, $\alpha$-zearalanol and $\beta$-zearalanol in traditional Chinese medicines by ultra-high-performance liquid chromatography-tandem mass spectrometry. Journal of Chromatography B, 879(5), 411-420. 
Ibáñez-Vea, M., González-Peñas, E., Lizarraga, E., \& De Cerain, A. L. (2012). Co-occurrence of aflatoxins, ochratoxin A and zearalenone in barley from a northern region of Spain. Food Chemistry, 132(1), 35-42.

Iqbal, S. Z., Asi, M. R., Jinap, S., \& Rashid, U. (2014). Detection of aflatoxins and zearalenone contamination in wheat derived products. Food Control, 35(1), 223-226.

Jiao, Y., Ding, L., Fu, S., Zhu, S., Li, H., \& Wang, L. (2012). Determination of bisphenol $\mathrm{A}$, bisphenol $\mathrm{F}$ and their diglycidyl ethers in environmental water by solid phase extraction using magnetic multiwalled carbon nanotubes followed by GC-MS/MS. Analytical Methods, 4(1), 291-298.

JECFA. Zearalenone. In: Joint FAO/WHO expert Committee on Food Additives. Safety Evaluation of Certain Food Additives and Contaminants. WHO/FAO Food additives Series 44. IPCS-International Programme on Chemical Safety. WHO, Geneva (2000).

Kosa, S. A., Al-Zhrani, G., \& Salam, M. A. (2012). Removal of heavy metals from aqueous solutions by multi-walled carbon nanotubes modified with 8-hydroxyquinoline. Chemical Engineering Journal, 181, 159-168.

Lucci, P., Derrien, D., Alix, F., Perollier, C., \& Bayoudh, S. (2010). Molecularly imprinted polymer solid-phase extraction for detection of zearalenone in cereal sample extracts. Anal Chim Acta, 672(1-2), 15-19.

Maaroufi, K., Chekir, L., Creppy, E. E., Ellouz, F., \& Bacha, H. (1996). Zearalenone induces modifications of haematological and biochemical parameters in rats. 

Toxicon, 34(5), 535-540.

Moreno, V., Zougagh, M., \& Ríos, Á. (2016). Hybrid nanoparticles based on magnetic multiwalled carbon nanotube-nanoC ${ }_{18} \mathrm{SiO}_{2}$ composites for solid phase extraction of mycotoxins prior to their determination by LC-MS. Microchimica Acta, 183(2), 871-880.

Oliveira, M. S., Rocha, A., Sulyok, M., Krska, R., \& Mallmann, C. A. (2016). Natural mycotoxin contamination of maize (Zea mays L.) in the South region of Brazil. Food Control.

Pleadin, J., Sokolović, M., Perši, N., Zadravec, M., Jaki, V., \& Vulić, A. (2012). Contamination of maize with deoxynivalenol and zearalenone in Croatia. Food Control, 28(1), 94-98.

Pyrzynska, K., Kubiak, A., \& Wysocka, I. (2016). Application of solid phase extraction procedures for rare earth elements determination in environmental samples. Talanta, 154, 15-22.

Qin, Y., Zhao, P., Fan, S., Han, Y., Li, Y., Zou, N., Song, S., Zhang, Y., Li, F., \& Li, X. (2015). The comparison of dispersive solid phase extraction and multi-plug filtration cleanup method based on multi-walled carbon nanotubes for pesticides multi-residue analysis by liquid chromatography tandem mass spectrometry. Journal of Chromatography A, 1385, 1-11.

Shier, W., Shier, A., Xie, W., \& Mirocha, C. (2001). Structure-activity relationships for human estrogenic activity in zearalenone mycotoxins. Toxicon, 39(9), $1435-1438$. 
Stahnke, H., Kittlaus, S., Kempe, G. n., \& Alder, L. (2012). Reduction of matrix effects in liquid chromatography-electrospray ionization-mass spectrometry by dilution of the sample extracts: how much dilution is needed? Analytical Chemistry, 84(3), 1474-1482.

Tarigh, G. D., \& Shemirani, F. (2013). Magnetic multi-wall carbon nanotube nanocomposite as an adsorbent for preconcentration and determination of lead (II) and manganese (II) in various matrices. Talanta, 115, 744-750.

Tralamazza, S. M., Bemvenuti, R. H., Zorzete, P., de Souza Garcia, F., \& Corrêa, B. (2016). Fungal diversity and natural occurrence of deoxynivalenol and zearalenone in freshly harvested wheat grains from Brazil. Food Chemistry, 196, 445-450.

Välimaa, A.-L., Kivistö, A. T., Leskinen, P. I., \& Karp, M. T. (2010). A novel biosensor for the detection of zearalenone family mycotoxins in milk. Journal of Microbiological Methods, 80(1), 44-48.

Vasconcelos, I., \& Fernandes, C. (2017). Magnetic solid phase extraction for determination of drugs in biological matrices. TRAC Trends in Analytical Chemistry, 89, 41-52.

Vidal, J. C., Bonel, L., Ezquerra, A., Hernández, S., Bertolín, J. R., Cubel, C., \& Castillo, J. R. (2013). Electrochemical affinity biosensors for detection of mycotoxins: A review. Biosensors and Bioelectronics, 49, 146-158.

Xu, Y., Ding, J., Chen, H., Zhao, Q., Hou, J., Yan, J., Wang, H., Ding, L., \& Ren, N. (2013). Fast determination of sulfonamides from egg samples using magnetic 
multiwalled carbon nanotubes as adsorbents followed by liquid chromatography-tandem mass spectrometry. Food Chemistry, 140(1), 83-90.

Yazdinezhad, S. R., Ballesteros-Gómez, A., Lunar, L., \& Rubio, S. (2013). Single-step extraction and cleanup of bisphenol A in soft drinks by hemimicellar magnetic solid phase extraction prior to liquid chromatography/tandem mass spectrometry. Analytica Chimica Acta, 778, $31-37$.

Yilmaz, E., Alosmanov, R., \& Soylak, M. (2015). Magnetic solid phase extraction of lead (II) and cadmium (II) on a magnetic phosphorus-containing polymer (M-PhCP) for their microsampling flame atomic absorption spectrometric determinations. RSC Advances, 5(43), 33801-33808.

Zhan, S., Huang, X., Chen, R., Li, J., \& Xiong, Y. (2016). Novel fluorescent ELISA for the sensitive detection of zearalenone based on $\mathrm{H}_{2} \mathrm{O}_{2}$-sensitive quantum dots for signal transduction. Talanta, 158, 51-56.

Zhang, H. F., \& Shi, Y. P. (2012). Preparation of $\mathrm{Fe}_{3} \mathrm{O}_{4}$ nanoparticle enclosure hydroxylated multi-walled carbon nanotubes for the determination of aconitines in human serum samples. Analytica Chimica Acta, 724, 54-60.

Zinedine, A., Soriano, J. M., Molto, J. C., \& Manes, J. (2007). Review on the toxicity, occurrence, metabolism, detoxification, regulations and intake of zearalenone: an oestrogenic mycotoxin. Food and Chemical Toxicology, 45(1), 1-18.

Zollner, P., Jodlbauer, J., \& Lindner, W. (1999). Determination of zearalenone in grains by high-performance liquid chromatography-tandem mass spectrometry 


\section{Figure captions}

526

Fig. 1 Schematic diagrams of magnetic solid-phase extraction (M-SPE) procedure.

(A) Transmission electron microscope (TEM) image of multi-walled carbon nanotubes-magnetic nanoparticles (MWCNT-MNPs).

Fig. 2 Recoveries of zearalenone (ZEA), $\alpha$-zearalenol ( $\alpha$-ZOL), $\beta$-zearalenol ( $\beta$-ZOL), zearalanone (ZAN), $\alpha$-zearalanol $(\alpha$-ZAL) and $\beta$-zearalanol $(\beta$-ZAL) in maize extracts purified by the M-SPE procedure using acetone, acetonitrile and methanol with $0.5 \%$ formic acid or $0.5 \%$ aqueous ammonia as the desorption solvent. Acceptable recoveries lay within the two dashed lines (70-120\%).

${ }^{a}$ represents the pure organic solvents; ${ }^{b}$ represents the organic solvents with $0.5 \%$ formic acid; ${ }^{c}$ represents the organic solvents with $0.5 \%$ aqueous ammonia.

Fig. 3 Recovery data for the investigated mycotoxins as a function of the major parameters affecting the purification efficiency of M-SPE procedure. (A) desorption solution volume, (B) the acetonitrile content in adsorption solution, (C) adsorption time, and (D) MWCNT-MNPs amount.

Fig. 4 Visually observable features (A) and matrix effects data (B) for six mycotoxins purified or not purified by magnetic solid-phase extraction (M-SPE) procedure. The tolerance level of matrix effects is in the range delineated by the two dashed lines $(80-120 \%)$. 

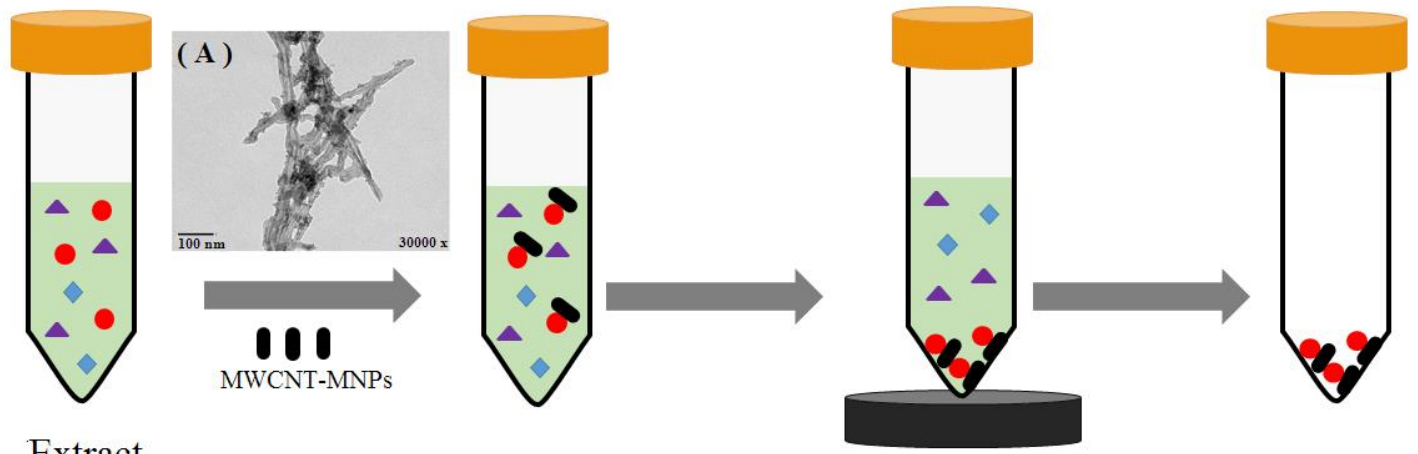

Extract

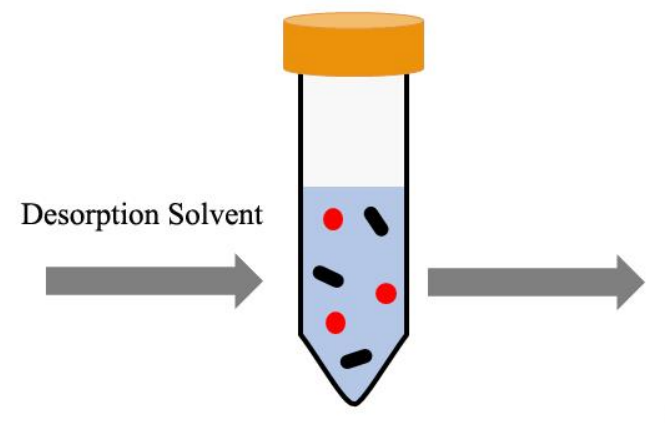

548

549

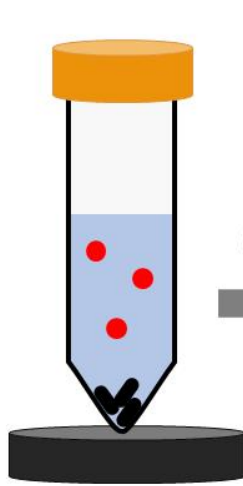

Magnet
Magnet

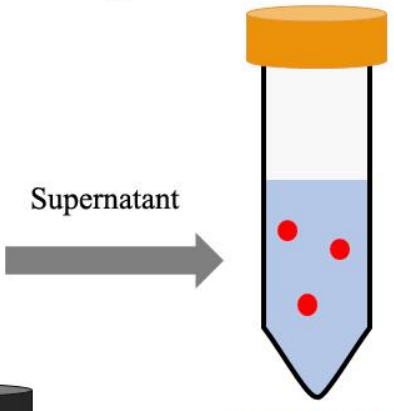

Ready for UHPLC-MS/MS Analysis

Fig. 1 


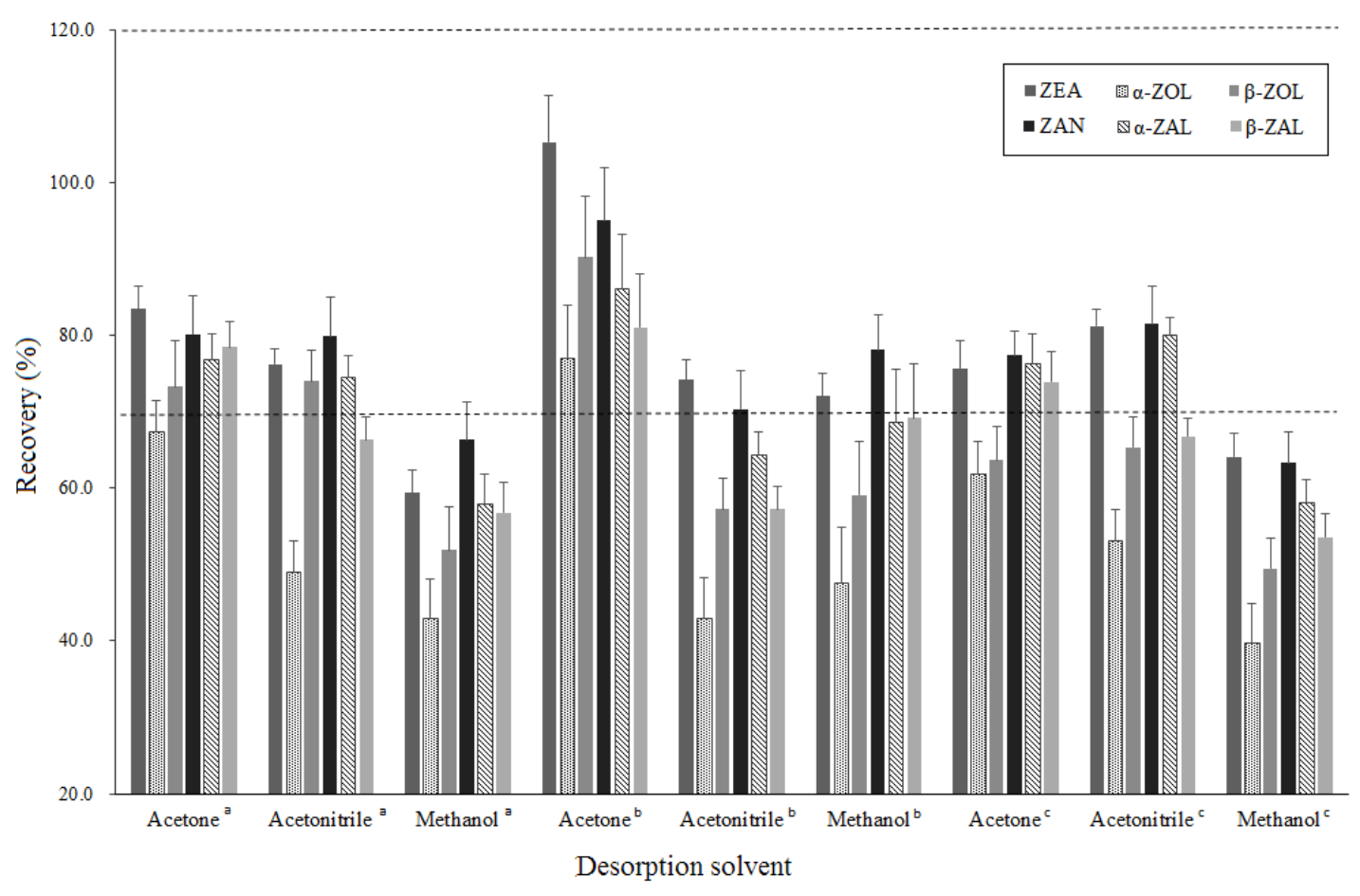

Fig. 2 

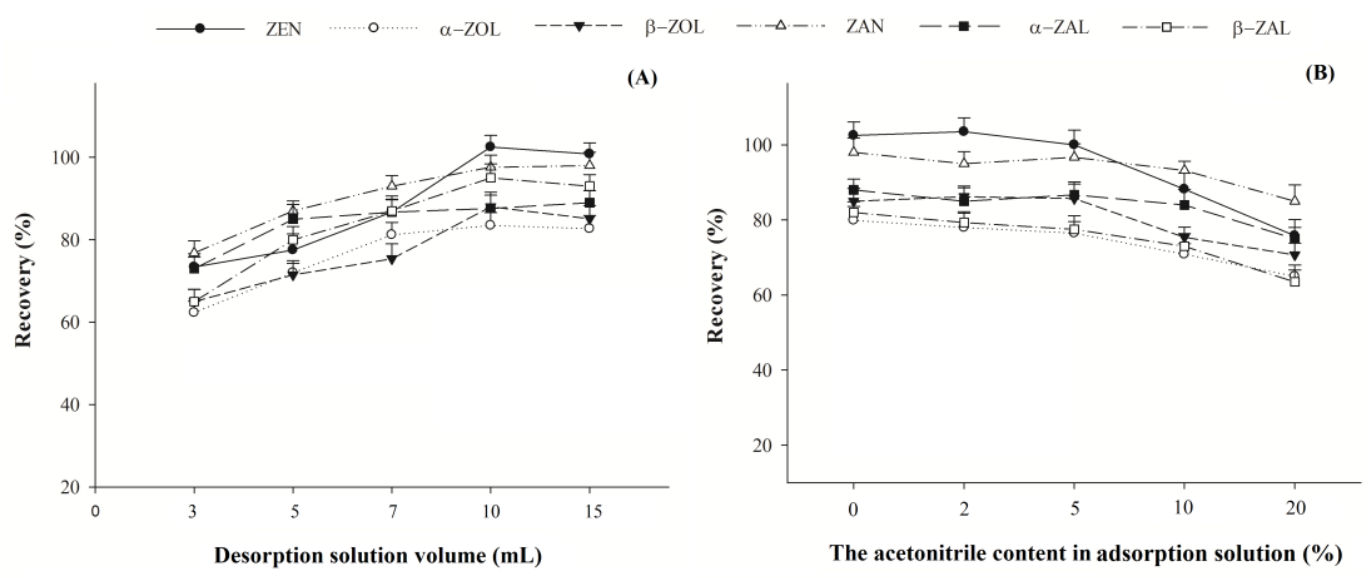

(C)

(D)
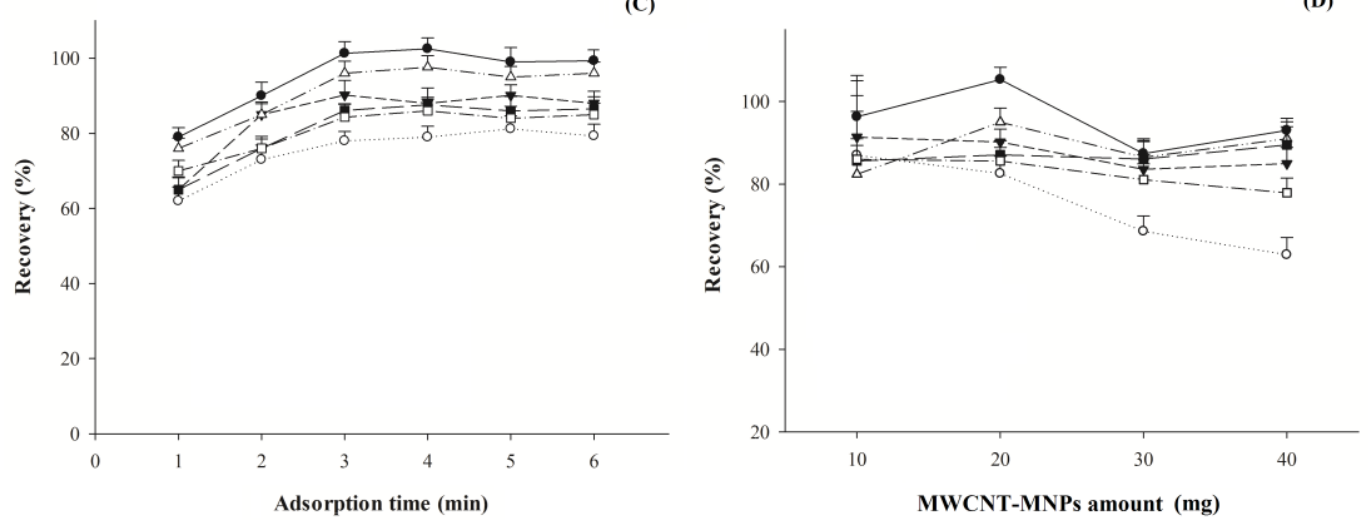

Fig. 3 

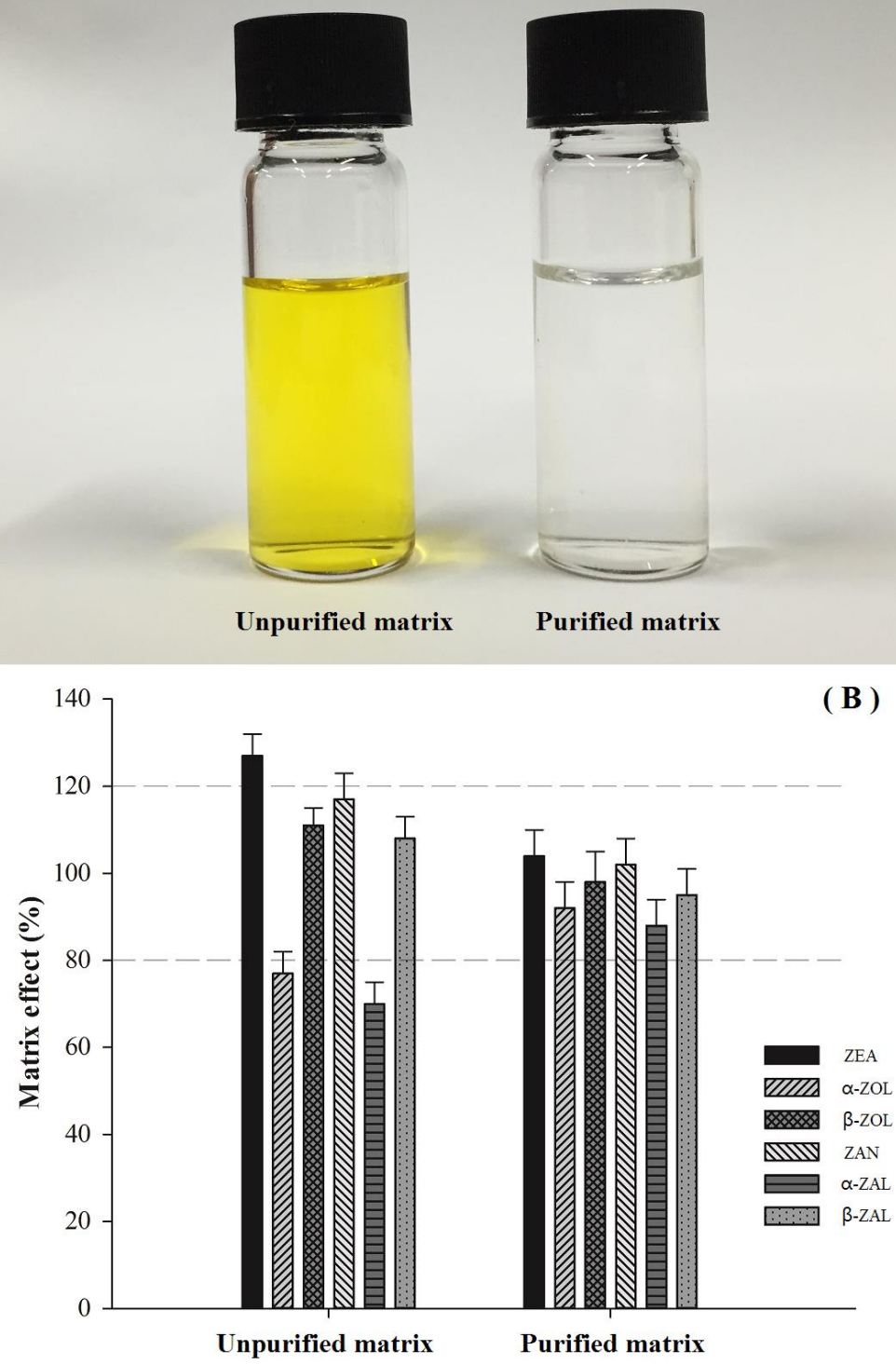

Fig. 4 
Table 1. Calibration curves of ZEA and its derivatives in acetonitrile

\begin{tabular}{ccccccc}
\hline Mycotoxin & $\begin{array}{c}\text { Slope } \\
\left.\overline{\boldsymbol{X}}_{ \pm \mathrm{SD}}\right)\end{array}$ & $\begin{array}{c}\text { Intercept } \\
\left(\overline{\boldsymbol{X}}_{ \pm \mathrm{SD}}\right)\end{array}$ & $\mathrm{R}^{2}$ & $\begin{array}{c}\text { Linear } \\
\text { range } \\
(\mathrm{ng} / \mathrm{mL})\end{array}$ & $\begin{array}{c}\mathrm{LOD}^{\mathrm{a}} \\
(\mu \mathrm{g} / \mathrm{kg})\end{array}$ & $\begin{array}{c}\mathrm{LOQ}^{\mathrm{b}} \\
(\mu \mathrm{g} / \mathrm{kg})\end{array}$ \\
\hline ZEA & $10130 \pm 1020$ & $2209 \pm 240$ & 0.998 & $0.1-500$ & 0.03 & 0.07 \\
$\alpha-$ ZOL & $2915 \pm 281$ & $663 \pm 301$ & 0.995 & $0.1-500$ & 0.04 & 0.10 \\
$\beta$-ZOL & $2248 \pm 138$ & $443 \pm 109$ & 0.996 & $0.1-500$ & 0.04 & 0.09 \\
ZAN & $5304 \pm 379$ & $1847 \pm 650$ & 0.996 & $0.1-500$ & 0.03 & 0.07 \\
$\alpha-Z A L$ & $2143 \pm 152$ & $345 \pm 98$ & 0.995 & $0.1-500$ & 0.04 & 0.10 \\
$\beta-Z$-ZAL & $1768 \pm 89$ & $932 \pm 203$ & 0.993 & $0.1-500$ & 0.04 & 0.10 \\
\hline
\end{tabular}

564

${ }^{\mathrm{a}}$ Limit of detection $(\mathrm{S} / \mathrm{N}=3)$

$565{ }^{\mathrm{b}}$ Limit of quantification $(\mathrm{S} / \mathrm{N}=10)$

566

567 
Table 2. Recovery, intra-day and inter-day precision data for ZEA and its derivatives in Maize

\begin{tabular}{|c|c|c|c|c|}
\hline Mycotoxin & $\begin{array}{c}\text { Spiked } \\
\text { concentration } \\
\text { levels }(\mu \mathrm{g} / \mathrm{kg})\end{array}$ & $\begin{array}{c}\text { Recovery } \\
\bar{X} \pm \text { SD } \\
(\%)\end{array}$ & $\begin{array}{l}\text { Intra-day } \\
\text { precision } \\
(\mathrm{RSD}, \%)\end{array}$ & $\begin{array}{l}\text { Inter-day } \\
\text { precision } \\
(\mathrm{RSD}, \%)\end{array}$ \\
\hline \multirow{3}{*}{ ZEA } & 5 & $100.5 \pm 6.9$ & 6.8 & 7.5 \\
\hline & 50 & $101.2 \pm 6.2$ & 6.1 & 11.5 \\
\hline & 200 & $104.1 \pm 4.9$ & 4.7 & 9.8 \\
\hline \multirow{3}{*}{$\alpha-Z O L$} & 5 & $81.1 \pm 4.3$ & 5.3 & 5.2 \\
\hline & 50 & $77.8 \pm 4.9$ & 6.2 & 10.6 \\
\hline & 200 & $80.5 \pm 4.6$ & 5.6 & 6.0 \\
\hline \multirow{3}{*}{$\beta-\mathrm{ZOL}$} & 5 & $80.2 \pm 3.9$ & 4.8 & 5.6 \\
\hline & 50 & $81.3 \pm 4.1$ & 5.0 & 9.1 \\
\hline & 200 & $80.5 \pm 9.0$ & 11.2 & 13.2 \\
\hline \multirow{3}{*}{ ZAN } & 5 & $94.0 \pm 4.6$ & 4.9 & 8.3 \\
\hline & 50 & $92.5 \pm 4.8$ & 5.2 & 6.1 \\
\hline & 200 & $94.8 \pm 3.5$ & 3.7 & 3.2 \\
\hline \multirow{3}{*}{$\alpha-Z A L$} & 5 & $77.6 \pm 3.6$ & 4.6 & 9.0 \\
\hline & 50 & $81.9 \pm 3.0$ & 3.7 & 4.1 \\
\hline & 200 & $79.8 \pm 2.7$ & 3.4 & 4.9 \\
\hline \multirow{3}{*}{$\beta-\mathrm{ZAL}$} & 5 & $75.8 \pm 4.0$ & 5.2 & 12.6 \\
\hline & 50 & $78.0 \pm 4.8$ & 6.1 & 7.5 \\
\hline & 200 & $76.9 \pm 3.2$ & 4.2 & 9.0 \\
\hline
\end{tabular}

